\title{
Research on Teaching Reform of Virtual Simulation Courses Based on Project
}

\author{
Shang Liu \\ Information Science and Technology Department, Tianjin University of Finance \& Economics, Tian \\ Jin, 300222, China \\ liushangw@aliyun.com
}

Keywords: Virtual Simulation Courses, Reform of Theory Teaching Method, Reform of Experiment Teaching Method

\begin{abstract}
It is difficult for student to master virtual simulation courses. With the development of the industry, many teachers have taken part in practical projects. So, this paper does research on the problem on how to integrate the project developing experience and knowledge and teaching methods. And it give reforms of theory teaching method, experiment teaching method, and graduation design. By these reforms, it can improve the ability of knowledge practical using and flexible control, which can meet the requirements of economic development needs
\end{abstract}

\section{Introduction}

With the development of virtual simulation technology, virtual simulation courses have become a teaching focus of computer Science College. Many colleges and universities have opened virtual simulation technology laboratories, which to meet the needs of teaching and research works, such as Tianjin University, Beijing Institute of Technology, Tianjin University of Finance Economics. At present, the virtual simulation courses include computer graphics, computer vision, multimedia technology, artificial intelligence, multimedia interface technology, etc. These courses contain a large number of theory methods, which is about using the computer to realize the visualization and simulation analysis of the decision-making, design and production process. These theory methods contain many concepts, which are extremely abstract and closely related to mathematics. So it is difficult for student to master them. But there is still a gap in the use of this knowledge to solve practical problems.

With the development of the industry, many teachers have taken part in practical projects. These projects include the reality of 3D garment simulation, virtual assembly of electric bicycle, simulation analysis of parts and components, etc. These projects are development in acceding to the needs of enterprises and are all around the Tianjin characteristic industry. The developers can archive rich experience and knowledge.

Based on the above analysis, this paper do the researches on the problem how to o integrate the project developing experience and knowledge and teaching methods. By this way, it can make full use of the resources in project development and normal teaching. And it can form new methods which are integration of industrialization, teaching and research. The new teaching methods can improve the ability of knowledge practical using and flexible control, which can meet the requirements of economic development needs.

\section{Reform of Theory Teaching Method Based On Project}

Project teaching method is proposed by Professor Katz and Professor Chad. It is a teaching method that is based on student-oriented. The content of the theory is that the learning process is not only the accumulation of knowledge, but also the formation of students in the action of the various experiences, experiences, etc. This theory indicates that study is not only a process of knowledge accumulation, but also a process of experience accumulation.

The teachers should analyze and arrange the curriculum firstly, and classify and restructure the 
theory knowledge according to characteristics of the course. The knowledge is classified as follows: the basic concept and principle, the algorithm, and comprehensive knowledge. According different type knowledge, three different teaching methods are used. And they are "situational teaching method" "case teaching method "and "interactive teaching method ".

"Situational teaching method" is used to teach basic concepts and principles. In order to strengthen understanding and mastering of theoretical knowledge, a project database is build according to the theoretical knowledge. The database consists of animation and video which are show the content of work principle, system structure, application background etc. By this way the abstract theoretical knowledge become concretely and visually. It can enhance the understanding of knowledge.

"Interactive teaching method" is adopted for algorithm knowledge. The relevant application problems are extracted from the actual project, which need to solve by student. A teacher is no longer a lecture, and is a guide. It let the students understand the knowledge from "study", "thinking" and "imagination" in the process of problem solving. In this process, teachers and students are actively exchange and interaction. It can create a learning environment for knowledge sharing and joint research. And it can enhance the initiative and creativity of study.

"Case teaching method" and "discussion method" is used for comprehensive knowledge teaching. Teachers should establish a project case corresponding to the knowledge points in advance. And the students are divided in team. The students are guided in the process of analysis, design, and implement according to the case. It's a comprehensive, systematic training. At the same time, the project development should pay attention to the integrated guidance about the idea, the organization, the methods, and skills etc. It is a training of computer application ability and project development thinking ability for student.

\section{Reform of Experiment Teaching Method Based on Project}

The main purpose of the experiment teaching is to strengthen understanding of the theoretical knowledge, and improve apply ability. It can be said that experimental teaching is an important cornerstone of the training mode of engineering students, and it is also one of the important links of acquisition of knowledge.

The train objective of course is divided into several tasks in our experiment teaching method. And every task can be implemented and closely related to the practical application. Then, every task is designed as an experiment topic which has explicit target and specific resource. The experiment topic should be correlated the theory and application. By these experiment topics, it can cultivate the students' ability to solve problem and self-learning, deep the understanding of knowledge.

There are two kinds of projects in experiment design: virtual project and actual project. The advantage of virtual project is closely with the teaching content. The disadvantage is lack of real application background and is simplified by human. So, it is not conducive to the cultivation of students to solve the problem flexibility and the ability of the practical training. The advantage of actual project is that has real application background. And it is complex and random. The shortcoming is that is related comprehensive knowledge, and it is difficult to correspond to the knowledge points one by one. So the actual project cannot be directly transplanted to the teaching process.

Base on the analysis above, this paper combines the virtual project and actual project to design the experiments. The method is modify the actual project in order to make it can correspond to the knowledge point.

\section{Reform of Graduation Design Based on Project}

Graduation design is an important link of college training. It not only can cultivate students' comprehensive use of knowledge and flexible use, but also can cultivate innovation ability, practical ability and teamwork cooperation consciousness by graduation design. And the reform method includes 3 parts as follows. 
1) Topic selection. The topic should be comprehensive, realistic and professional. A comprehensive topic contains knowledge of relevant different subjects. Students can get the integration of experience by implement subject. A realistic topic has real application background. A professional topic should be design according to the actual content and requirements of virtual simulation job in company.

2) The students take part in the graduation design in the form of team. In this way, each student is responsible for a part of the project. Whether the entire project will be completed successfully or not, this depends on whether every subsystem is completed. So, each member of the team should work together to achieve common goals. This undergraduate graduation form is designed based on the issue and problem solving, which belongs to PBL (Based Learning Problem).By this way , it is not only cultivate the team cooperation ability, but also cultivate the ability to "sell" ideas and carry out ideas.

3) It is taken double tutor system of schools and enterprises to guide graduation design. The school teacher is the main guide; they are responsible for the general management, design content and thesis writing. The enterprises teacher take part in the follow works: topic selections coordinate the relationship between the students and work place, and simulation of enterprise project operation mode. That is to say, they give guidance to student in the perspective of engineering practice. This reform can improve the quality of graduation design and practical ability, strengthen the contact between the school and enterprises, and improve the degree of social acceptance of graduates.

\section{Conclusion}

In this paper, the research on the reform of the teaching method based on the project of virtual simulation is carried out. Its object is combining the project implements and teaching methods. The classical teaching method is reformed by importing the practical experience and the knowledge of project implements. It can make full use of the teaching resources in different environment. Reform methods are integration of industrialization, teaching and research. And it can improve the ability of knowledge practical using and flexible control, which can meet the requirements of economic development needs.

\section{Acknowledgement}

In this paper, the research was sponsored by the Nature Science Foundation of Henan Province (Project No. 201112400450401) and Youth Fund Project of Luoyang Institute of Science and Technology (Project No. 2010QZ16).

\section{References}

[1] Brandon AF, All AC, Constructivism theory analysis and application to curricula, Nursing Education Perspectives,2010, 31 89-92.

[2] DU Jingna, Application of Humanism Theory in the Teaching Approach, Higher Education of Social Science[J],2012,3(1) 32-36.

[3] Stocking $\mathrm{P}$ J, The teaching of aerospace vehicle design at cranfield university with particular reference to the group design project[J], Pro IMechE Part G:Aerospace Enineeing,2007,221:225-23.

[4] JP Fielding, RI Jones, Graduate-level design education, based on flight demonstrator projects[J], Aircraft Design,2000, 3(4) 217-238.

[5] Gert Pasman, Ingrid Mulder, Bringing the everyday life into engineering education[J], International Journal of Advanced Corporate Learning. 2011, 4(11) 25-31. 